\title{
Pyrogallol-induced endothelial cell death is related to GSH depletion rather than ROS level changes
}

\author{
YONG HWAN HAN, HWA JIN MOON, BO RA YOU, SUNG ZOO KIM, SUHN HEE KIM and WOO HYUN PARK
}

Department of Physiology, Medical School, Centers for Healthcare Technology Development Institute for Medical Sciences Chonbuk National University, Jeonju 561-180, Republic of Korea

Received August 12, 2009; Accepted October 9, 2009

\author{
DOI: $10.3892 /$ or_00000635
}

\begin{abstract}
Pyrogallol (PG) as a polyphenol compound induces apoptosis in several types of cells. Here, we evaluated the effects of PG on endothelial cells (ECs), especially calf pulmonary artery endothelial cells (CPAEC) in relation to the cell growth, ROS and glutathione (GSH) levels. PG dosedependently inhibited the growth of CPAEC and human umbilical vein endothelial cells (HUVEC) at $24 \mathrm{~h}$. PG also induced apoptosis in CPAEC, which was accompanied by the loss of mitochondrial membrane potential (MMP; $\Delta \Psi_{\mathrm{m}}$ ). PG decreased ROS level including $\mathrm{O}_{2}{ }^{-}$and PG dose-dependently increased GSH depleted cell number in both EC types. Nacetyl-cysteine (NAC; a well-known antioxidant) increased ROS levels in PG-treated CPAEC with the prevention of cell death and GSH depletion. In conclusion, PG inhibited the growth of ECs, especially CPAEC via apoptosis. PG-induced EC death was related to GSH depletion rather than ROS level changes.
\end{abstract}

\section{Introduction}

Pyrogallol (PG) as a polyphenol compound is known as a superoxide anion $\left(\mathrm{O}_{2}{ }^{-}\right)$generator $(1,2)$. The $\mathrm{O}_{2}{ }^{-}$belongs to the

Correspondence to: Dr Woo Hyun Park, Department of Physiology, Medical School, Chonbuk National University, Jeonju 561-180, Republic of Korea

E-mail: parkwh71@chonbuk.ac.kr

Abbreviations: PG, pyrogallol; EC, endothelial cells; CPAEC, calf pulmonary arterial endothelial cells; HUVEC, human umbilical vein endothelial cells; ROS, reactive oxygen species; MMP $\left(\Delta \Psi_{\mathrm{m}}\right)$, mitochondrial membrane potential; NADPH, nicotine adenine diphosphate; XO, xanthine oxidase; SOD, superoxide dismutase; FBS, fetal bovine serum; MTT, 3-(4,5-dimethylthiazol-2-yl)-2,5diphenyltetrazolium bromide; PI, propidium iodide; FITC, fluorescein isothiocyanate; H2DCFDA, 2',7'-dichlorodihydrofluorescein diacetate; DHE, dihydroethidium; GSH, glutathione; CMFDA, 5chloromethylfluorescein diacetate; NAC, N-acetyl cysteine; BSO, L-buthionine sulfoximine

Key words: pyrogallol, apoptosis, endothelial cells, reactive oxygen species, glutathione reactive oxygen species (ROS) including hydrogen peroxide $\left(\mathrm{H}_{2} \mathrm{O}_{2}\right)$ and hydroxyl radical $\left({ }^{\circ} \mathrm{OH}\right)$. ROS have recently been implicated in the regulation of many important cellular events, including transcription factor activation, gene expression, differentiation and cell proliferation $(3,4)$. ROS are formed as by-products of mitochondrial respiration or certain oxidases such as nicotine adenine diphosphate (NADPH) oxidase, xanthine oxidase $(\mathrm{XO})$, and a number of arachidonic acid oxygenases (5). A change in the redox state of the tissue and cell implies a change in the generation or metabolism of ROS. The principal metabolic pathways include superoxide dismutase (SOD), expressed as extracellular, cytoplasmic and mitochondrial isoforms (6), which metabolize $\mathrm{O}_{2}{ }^{--}$to $\mathrm{H}_{2} \mathrm{O}_{2}$. Further metabolism by peroxidases, including catalase and glutathione (GSH) peroxidase, yields $\mathrm{O}_{2}$ and $\mathrm{H}_{2} \mathrm{O}$ (7). Cells possess antioxidant systems to control the redox state, which is important for their survival. Excessive production of ROS gives rise to the activation of events leading to death in several cell types $(8,9)$. PG induces $\mathrm{O}_{2}{ }^{-}-$-mediated death of several types of cells such as mesangial cells (10), human lymphoma cells (1), human glioma cells (11) and Calu-6 lung cancer cells $(12,13)$.

Vascular endothelium is involved in various regulatory responsibilities such as blood pressure, inflammation and angiogenesis (14). Fundamental to the transition of tumors from a latent to malignant state, angiogenesis involving formation of new blood vessels from pre-existing vasculature is a crucial part. The proliferation of endothelium cells (ECs; sprouting) is the early step of angiogenesis. Despite critical roles for vascular ECs in tumor biogenesis and progression, the effects of polyphenol compounds, especially PG on ECs remain relatively poorly understood.

In the present study, we evaluated the effects of PG on ECs, especially calf pulmonary artery endothelial cells (CPAEC) in relation to cell death, ROS and GSH.

\section{Materials and methods}

Cell culture. Calf normal pulmonary artery endothelial cells (CPAEC) from KCLB (Korean Cell Line Bank) and primary human umbilical vein endothelial cells (HUVEC) from PromoCell GmbH (Heidelberg, Germany) were maintained in humidified incubator containing $5 \% \mathrm{CO}_{2}$ at $37^{\circ} \mathrm{C}$. CPAEC were cultured in RPMI-1640 supplemented with $10 \%$ fetal bovine serum (FBS) and $1 \%$ penicillin-streptomycin (Gibco 
BRL, Grand Island, NY). CPAEC were routinely grown in 100-mm plastic tissue culture dishes (Nunc, Roskilde, Denmark) and harvested with a solution of trypsin-EDTA (Gibco BRL) while in a logarithmic phase of growth. CPAEC were maintained in these culture conditions for all experiments. HUVEC were cultured in complete endothelial cell growth medium (ECGM, PromoCell) with 2\% FBS. HUVEC were washed and detached with HepesBSS (30 mM Hepes), trypsin-EDTA and trypsin neutralization solution (Promocell). HUVEC were used between passages four and six.

Reagents. PG was purchased from the Sigma-Aldrich Chemical Company (St. Louis, MO). PG was dissolved in $\mathrm{H}_{2} \mathrm{O}$ at $100 \mathrm{mM}$ as a stock solution. $\mathrm{N}$-acetyl-cysteine (NAC) and L-buthionine sulfoximine (BSO) were obtained from Sigma. NAC and BSO were dissolved in the buffer [20 mM HEPES ( $\mathrm{pH} 7.0)]$ and $\mathrm{H}_{2} \mathrm{O}$ at $100 \mathrm{mM}$ as a stock solution, respectively. Cells were pretreated with NAC and BSO for 30 min prior to PG treatment. DMSO $(0.2 \%)$ was used as a control vehicle. All stock solutions were wrapped in foil and kept at $-20^{\circ} \mathrm{C}$.

Cell growth assay. The effect of drugs on EC growth was determined by measuring 3-(4,5-dimethylthiazol-2-yl)-2,5diphenyltetrazolium bromide (MTT) dye absorbance of living cells as previously described (15). In brief, $3 \times 10^{4}$ cells per well were seeded in 96-well microtiter plates (Nunc). After exposure to the indicated amounts of PG with or without $2 \mathrm{mM}$ NAC or $10 \mu \mathrm{M}$ BSO for $24 \mathrm{~h}, 20 \mu 1$ of MTT (Sigma) solution ( $2 \mathrm{mg} / \mathrm{ml}$ in PBS) was added to each well of 96-well plates. The plates were incubated for 4 additional hours at $37^{\circ} \mathrm{C}$. MTT solution in the medium was aspirated and $200 \mu 1$ of DMSO were added to each well to solubilize the formazan crystals formed in viable cells. Optical density was measured at 570 nm using a microplate reader (Spectra MAX 340, Molecular Devices Co, Sunnyvale, CA).

Detection of intracellular ROS and $\mathrm{O}_{2}^{-*}$ levels. Intracellular ROS were detected by means of an oxidation-sensitive fluorescent probe dye, 2',7'-dichlorodihydrofluorescein diacetate $\left(\mathrm{H}_{2} \mathrm{DCFDA}\right.$; Ex/Em=495/529 nm) (Invitrogen Molecular Probes, Eugene, OR). $\mathrm{H}_{2}$ DCFDA is poorly selective for $\mathrm{O}_{2}{ }^{-}$. In contrast, dihydroethidium (DHE) $(\mathrm{Ex} / \mathrm{Em}=518 / 605$ $\mathrm{nm}$ ) (Invitrogen Molecular Probes) is highly selective for $\mathrm{O}_{2}{ }^{-}$- among ROS. In brief, $1 \times 10^{6}$ cells in 60-mm dish (Nunc) were incubated with the indicated amounts of PG with or without $2 \mathrm{mM}$ NAC or $10 \mu \mathrm{M}$ BSO for $24 \mathrm{~h}$. Cells were then washed in PBS and incubated with $20 \mu \mathrm{M} \mathrm{H}_{2}$ DCFDA or $\mathrm{DHE}$ at $37^{\circ} \mathrm{C}$ for $30 \mathrm{~min}$ according to the instructions of the manufacturer. DCF and DHE fluorescences were detected using a FACStar flow cytometer (Becton-Dickinson). ROS and $\mathrm{O}_{2}{ }^{-}$levels were expressed as mean fluorescence intensity (MFI), which was calculated by CellQuest software.

Detection of the intracellular glutathione (GSH). Cellular GSH levels were analyzed using 5-chloromethylfluorescein diacetate (CMFDA, Molecular Probes) $(\mathrm{Ex} / \mathrm{Em}=522 / 595 \mathrm{~nm})$ as previously described (16). In brief, $1 \times 10^{6}$ cells in $60-\mathrm{mm}$ dish were incubated with the indicated amounts of PG with or without $2 \mathrm{mM}$ NAC or $10 \mu \mathrm{M}$ BSO for $24 \mathrm{~h}$. Cells were then washed with PBS and incubated with $5 \mu \mathrm{M} \mathrm{CMFDA}$ at $37^{\circ} \mathrm{C}$ for $30 \mathrm{~min}$. CMF fluorescence intensity was determined using a FACStar flow cytometer (Becton-Dickinson). Negative CMF staining (GSH depleted) cells were expressed as the percent of (-) CMF cells. CMF levels in cells except GSH depleted cells were expressed as mean fluorescence intensity (MFI), which was calculated by CellQuest software.

Annexin $V$ staining. Apoptosis was determined by staining cells with annexin V-fluorescein isothiocyanate (FITC) $(\mathrm{Ex} / \mathrm{Em}=488 / 519 \mathrm{~nm})$, as previously described (13). In brief, $1 \times 10^{6}$ cells in $60-\mathrm{mm}$ dish were incubated with the indicated amounts of PG with or without $2 \mathrm{mM}$ NAC or $10 \mu \mathrm{M}$ BSO for $24 \mathrm{~h}$. Cells were washed twice with cold PBS and then resuspended in $500 \mu \mathrm{l}$ of binding buffer (10 mM HEPES/ $\mathrm{NaOH} \mathrm{pH} 7.4,140 \mathrm{mM} \mathrm{NaCl}, 2.5 \mathrm{mM} \mathrm{CaCl}_{2}$ ) at a concentration of $1 \times 10^{6}$ cells $/ \mathrm{ml}$. Five microliters of annexin V-FITC (PharMingen, San Diego, CA) was then added to these cells, which were analyzed with a FACStar flow cytometer (Becton-Dickinson).

Measurement of MMP $\left(\Delta \Psi_{m}\right)$. MMP $\left(\Delta \Psi_{\mathrm{m}}\right)$ levels were measured by Rhodamine 123 fluorescent dye $(\mathrm{Ex} / \mathrm{Em}=$ $485 / 535 \mathrm{~nm}$ ), as previously described (17). In brief, $1 \times 10^{6}$ cells in $60-\mathrm{mm}$ dish were incubated with the indicated amounts of PG with or without $2 \mathrm{mM}$ NAC or $10 \mu \mathrm{M}$ BSO for $24 \mathrm{~h}$. Cells were washed twice with PBS and incubated with Rhodamine $123(0.1 \mu \mathrm{g} / \mathrm{ml}$; Sigma $)$ at $37^{\circ} \mathrm{C}$ for $30 \mathrm{~min}$. Rhodamine 123 staining intensity was determined by flow cytometry. Rhodamine 123-negative cells indicate the loss of MMP $\left(\Delta \Psi_{\mathrm{m}}\right)$ in cells, which was calculated by CellQuest software.

Statistical analysis. The results represent the mean of at least two independent experiments; bar, SD. The data were analyzed using Instat software (GraphPad Prism4, San Diego, CA). The student's t-test or one-way analysis of variance (ANOVA) with post hoc analysis using Tukey's multiple comparison test was used for parametric data. The statistical significance was defined as $\mathrm{P}<0.05$.

\section{Results}

Effects of $P G$ on cell growth and intracellular ROS levels in $C P A E C$ and HUVEC. We examined the effect of PG on the growth of ECs by an MTT assay. Dose-dependent reduction of cell growth was observed in CPAEC and HUVEC with an $\mathrm{IC}_{50}$ of $\sim 50$ and $200 \mu \mathrm{M}$ at $24 \mathrm{~h}$, respectively (Fig. 1A and B). CPAEC was more sensitive to PG than HUVEC. To assess levels of intracellular ROS in PG-treated ECs at $24 \mathrm{~h}$, we used $\mathrm{H}_{2}$ DCFDA and DHE. As shown in Fig. $1 \mathrm{C}$ and D, DCF (ROS) levels were decreased in both ECs treated with PG. At $100 \mu \mathrm{M}$ PG-treated ECs, ROS was decreased in CPAEC, but not altered in HUVEC (Fig. 1C and D). The level of red fluorescence derived from DHE, which reflected $\mathrm{O}_{2}{ }^{-}$accumulation, was decreased in 30 or $50 \mu \mathrm{M}$ PG-treated CPAEC and increased in $100 \mu \mathrm{M}$ PG-treated CPAEC (Fig. 1E). While 100 or $200 \mu \mathrm{M}$ PG did not increase $\mathrm{O}_{2}{ }^{--}$level in HUVEC, $400 \mu \mathrm{M}$ PG increased the level (Fig. 1F). 
A

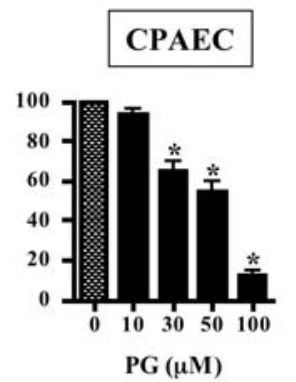

C

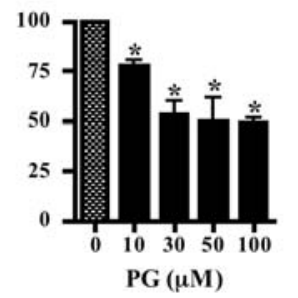

$\mathbf{E}$

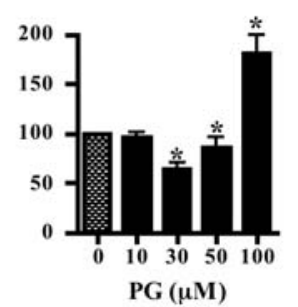

B

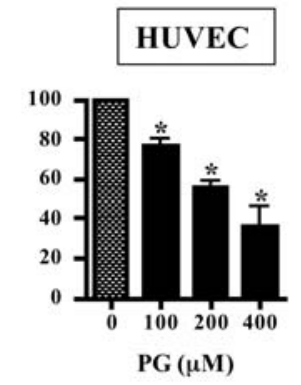

D

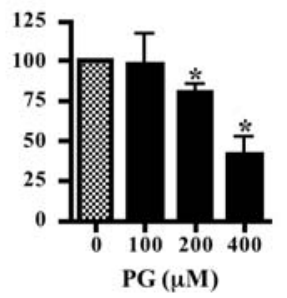

$\mathbf{F}$
A

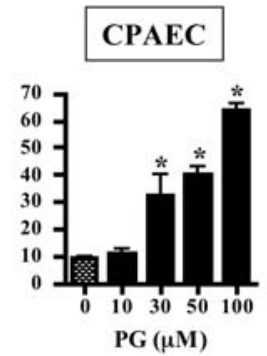

C

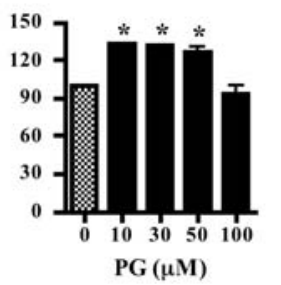

B

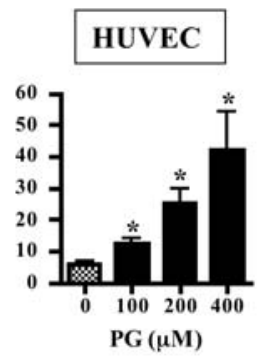

D

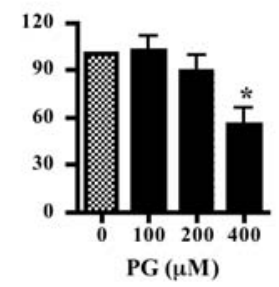

Figure 2. Effects of PG on GSH levels in ECs. Exponentially-growing cells were treated with the indicated concentrations of PG for $24 \mathrm{~h}$. GSH levels in ECs were measured using a FACStar flow cytometer. (A and B) Graphs show the percent of (-) CMF (GSH depleted) cells in CPAEC and HUVEC, respectively. (C and D) Graphs indicate mean CMF (GSH) levels (\%) in CPAEC and HUVEC except (-) CMF (GSH depleted) cells compared with each control group cell, respectively. ${ }^{*} \mathrm{P}<0.05$ compared with the $\mathrm{PG}$-untreated control cell group.

Apoptosis is closely related to the collapse of $\mathrm{MMP}\left(\Delta \Psi_{\mathrm{m}}\right)$ Figure 1. Effects of PG on cell growth and ROS levels in ECs. Exponentiallygrowing cells were treated with the indicated concentrations of PG for $24 \mathrm{~h}$. (A and B) Cell growths were assessed by an MTT assay. (C and D) ROS levels in ECs were measured using a FACStar flow cytometer. Graphs indicate DCF (ROS) levels (\%) in CPAEC and HUVEC compared with each control group cell, respectively. (E and F) Graphs indicate DHE $\left(\mathrm{O}_{2}^{-}\right)$levels (\%) in CPAEC and HUVEC compared with each control group cell, respectively. ${ }^{*} \mathrm{P}<0.05$ compared with the PG-untreated control cell group.

Effects of PG on GSH levels in CPAEC. Next, we analyzed the changes of GSH levels in ECs using CMF fluorescence dye. Treatment with PG increased the number of GSH depleted cells in CPAEC and HUVEC (Fig. 2A and B). At $100 \mu \mathrm{M}$ PG-treated ECs, GSH depleted cell number in CPAEC was increased $\sim 55 \%$ compared with PG-untreated control CPAEC and the number in HUVEC was increased no $>5 \%$ (Fig. 2A and B). When CMF (GSH) levels in ECs except negative CMF staining cells were assessed, GSH level was increased in 10-50 $\mu \mathrm{M}$ PG-treated CPAEC whereas the level was decreased in $100 \mu \mathrm{M}$ PG-treated CPAEC (Fig. 2C). In HUVEC, 200 or $400 \mu$ M PG decreased GSH level (Fig. 2D).

Effects of NAC and BSO on cell growth, cell death and MMP $\left(\triangle \Psi_{m}\right)$ in $P G$-treated CPAEC. Because the relatively lower doses of PG changed ROS and GSH levels in CPAEC, we assessed the effects of NAC (a well-known antioxidant) and BSO [an inhibitor of GSH synthesis (18)] on the growth of $50 \mu \mathrm{M}$ PG-treated CPAEC at $24 \mathrm{~h}$. NAC but not BSO significantly prevented the growth inhibition of CPAEC by PG (Fig. 3A). In addition, NAC but not BSO reduced the number of annexin V-FITC-positive cells in PG-treated CPAEC (Fig. 3B). BSO alone increased the number in control CPAEC (Fig. 3B). (19). Therefore, we determined MMP $\left(\Delta \Psi_{\mathrm{m}}\right)$ levels in PGtreated CPAEC. As expected, the loss of MMP $\left(\Delta \Psi_{\mathrm{m}}\right)$ (negative Rhodamine 123 cells) was observed in PG-treated CPAEC at $24 \mathrm{~h}$ (Fig. 3C). While NAC strongly prevented the loss of $\operatorname{MMP}\left(\Delta \Psi_{\mathrm{m}}\right)$ by PG, BSO did not (Fig. 3C).

Effects of NAC and BSO on ROS and GSH levels in PG-treated $C P A E C$. We assessed whether ROS and GSH levels in PGtreated CPAEC were changed by NAC or BSO at $24 \mathrm{~h}$. As shown in Fig. 4A, ROS (DCF) level in PG-treated CPAEC was significantly increased by NAC whereas NAC alone decreased ROS (DCF) level in control CPAEC. $\mathrm{O}_{2}{ }^{-}$level in PG-treated CPAEC was not altered by NAC or BSO (Fig. 4B). BSO alone significantly increased the level in control CPAEC (Fig. 4B). In relation to GSH level, NAC significantly prevented GSH depletion induced by PG (Fig. 4C). However, BSO did not affect the number in PG-treated CPAEC but increased the number in PG-untreated CPAEC (Fig. 4C). In addition, NAC increased GSH level in PG-treated CPAEC whereas BSO reduced GSH level in these cells (Fig. 4D).

\section{Discussion}

In the present study, we focused on evaluating the effects of PG on the growth of ECs, especially CPAEC in relation to cell death, ROS and GSH. Dose-dependent reduction of cell growth was observed in CPAEC and HUVEC with an $\mathrm{IC}_{50}$ of $\sim 50$ and $200 \mu \mathrm{M}$ at $24 \mathrm{~h}$, respectively (Fig. 1A and B). CPAEC was more sensitive to PG than HUVEC. The difference of susceptibility to PG between these ECs is probably due to the different basal activities of mitochondria and antioxidant enzymes depending on cell type, tissue origin and species (20). 
A

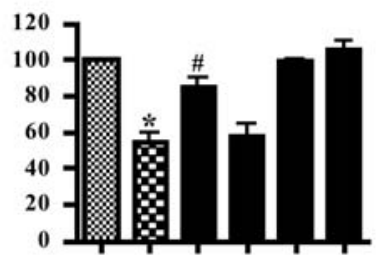

B

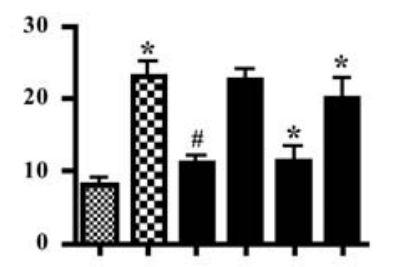

C

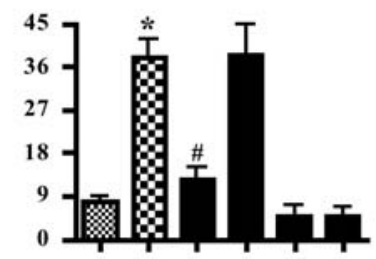

PG $50 \mu \mathrm{M}:-+++-$

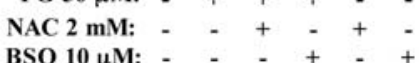

Figure 3. Effects of NAC and BSO on the cell growth, cell death and MMP $\left(\triangle \Psi_{\mathrm{m}}\right)$ in PG-treated CPAEC. Exponentially-growing CPAEC were treated with PG for $24 \mathrm{~h}$ following 30 min pre-incubation of $2 \mathrm{mM} \mathrm{NAC}$ or $10 \mu \mathrm{M}$ BSO. (A) Graph shows the cell growth, as assessed by an MTT assay. (B) Graph shows the percents of annexin V-FITC staining cells. (C) The graph shows the percents of Rhodamine 123 negative [MMP $\left(\Delta \Psi_{\mathrm{m}}\right)$ loss] cells, as measured with a FACStar flow cytometer. ${ }^{*} \mathrm{P}<0.05$ compared with the control group. ${ }^{\#} \mathrm{P}<0.05$ compared with cells treated with PG only.

A

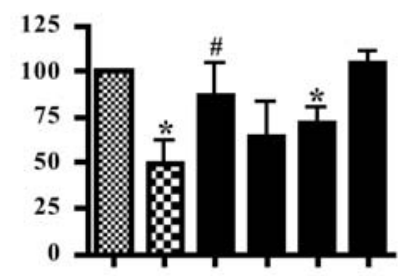

C

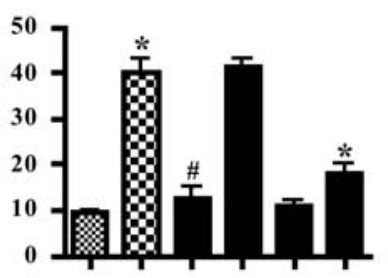

PG $50 \mu \mathrm{M}:-+++-$

NAC 2 mM: - - + - + -
PG induces apoptosis in several types of cells such as mesangial cells (10), human lymphoma cells (1), human glioma cells (11) and Calu-6 lung cancer cells $(12,13)$. PG also triggered the loss of MMP $\left(\Delta \Psi_{\mathrm{m}}\right)$ in Calu-6 lung cancer cells $(12,13)$. Likewise, PG induced apoptosis and the loss of MMP $\left(\Delta \Psi_{\mathrm{m}}\right)$ in CPAEC. PG can disturb the natural oxidation and reduction equilibrium in cells. For example, the increased patterns in $\mathrm{O}_{2}{ }^{-}$levels by PG were reported in pheochromocytoma PC12 cells (2), neuroblastoma SH-SY5Y cells (21), Calu-6 cells (22) and juxtaglomerular As4.1 cells (23). These data suggest that the apoptotic effects of PG are generally correlated with the changes of intracellular $\mathrm{O}_{2}{ }^{-}$levels. According to our current results, DCF (ROS) levels were decreased in both ECs treated with PG. $\mathrm{O}_{2}{ }^{-}$level was decreased in $50 \mu \mathrm{M}$ PG-treated CPAEC and increased by $100 \mu \mathrm{M}$ PG. While 100 or $200 \mu \mathrm{M}$ PG did not increase $\mathrm{O}_{2}{ }^{-}$level in HUVEC, $400 \mu \mathrm{M}$ PG increased the level. These results suggest that PG can affect the levels of different ROS depending on the cell type and incubation dose. Especially, $50 \mu \mathrm{M}$ PG showing apoptotic effect on CPAEC did not increase the $\mathrm{O}_{2}{ }^{-}$ level. In addition, although 100 or $200 \mu \mathrm{M}$ PG induced HUVEC death (data not shown), these doses of PG did not increase the $\mathrm{O}_{2}{ }^{-}$level. Therefore, our data suggest that the changes of ROS levels including $\mathrm{O}_{2}{ }^{-}$by PG are not related to CPAEC and HUVEC death.

Furthermore, NAC but not BSO significantly prevented the growth inhibition of CPAEC by PG. In addition, NAC but not BSO decreased apoptosis and the loss of MMP $\left(\Delta \Psi_{\mathrm{m}}\right)$ induced by PG. Interestingly, NAC increased ROS levels in PG-treated CPAEC but decreased the level in PG-untreated CPAEC. It is reported that some substances that have been regarded as antioxidant agents, such as ascorbic acid and tannic acid, can stimulate the generation of ROS under certain circumstances

B

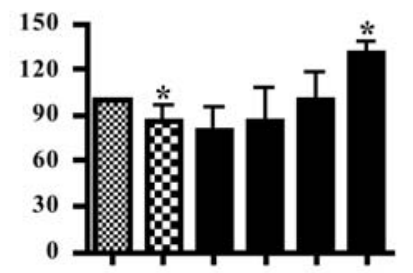

D

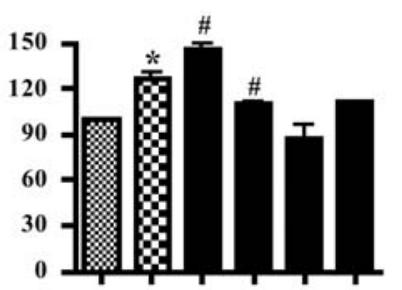

PG 50 $\mu \mathrm{M}:-+++-$

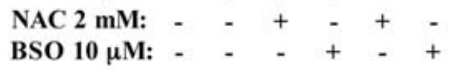

Figure 4. Effects of NAC and BSO on ROS and GSH levels in PG-treated CPAEC. Exponentially-growing CPAEC were treated with PG for 24 h following $30 \mathrm{~min}$ pre-incubation of $2 \mathrm{mM}$ NAC or $10 \mu \mathrm{M}$ BSO. ROS and GSH levels in CPAEC were measured using a FACStar flow cytometer. (A and B) Graphs indicate DCF (ROS) and DHE $\left(\mathrm{O}_{2}^{*}\right)$ levels (\%) compared with control CPAEC, respectively. (C and D) Graphs show the percents of (-) CMF (GSH depleted) cells (C) and mean CMF (GSH) levels compared with control CPAEC (D). ${ }^{*} \mathrm{P}<0.05$ compared with the control group. ${ }^{\sharp} \mathrm{P}<0.05$ compared with cells treated with $\mathrm{PG}$ only. 
$(24,25)$. According to unpublished data, NAC increased ROS levels in propyl gallate-treated CPAEC but decreased the level in MG132, a proteasome inhibitor-treated CPAEC. Therefore, it is considered that NAC acts as a pro-oxidant in CPAEC under PG treatment. BSO slightly altered ROS level in PGtreated CPAEC regardless of cell death change. These results also suggest that the changes of ROS levels in PG-treated CPAEC by NAC or BSO are not correlated with CPAEC death. In particular, BSO alone increased annexin V-FITC-positive cell numbers and $\mathrm{O}_{2}{ }^{-}$level in control CPAEC. Therefore, the exact role of ROS in PG-induced EC death needs to be defined further.

It has been reported that the intracellular GSH content has a decisive effect on anticancer drug-induced apoptosis, indicating that apoptotic effects are inversely proportional to GSH content (26). Likewise, PG increased the number of GSH depleted cells in CPAEC and HUVEC. At $100 \mu \mathrm{M}$ PG-treated ECs, GSH depleted cell number was strongly increased in CPAEC but not in HUVEC. These results seem to be correlated with MTT assay results from ECs treated with PG. Interestingly, GSH level in CPAEC was increased by treatment with the lower doses of PG. Probably, the relative GSH increase resulted from the lower consumption of GSH due to the decreased ROS level by PG. It is known that NAC containing a thiol group is a GSH precursor. NAC significantly prevented GSH depletion and slightly increased GSH levels in PG-treated CPAEC. NAC used in this study seems to be a GSH precursor rather than a ROS scavenger, although intracellular ROS level is tightly regulated by GSH level. BSO as a GSH synthesis inhibitor did not increase GSH depleted cell number in PG-treated CPAEC but significantly increased the number in control CPAEC. In addition, BSO reduced GSH level in PG-treated CPAEC but not in PG-untreated CPAEC. Other reports show that $100 \mu \mathrm{M}$ and $1 \mathrm{mM}$ BSO respectively, decreased GSH level in MCF breast cancer cells (27) and U937 leukemia cells (28). According to our recent studies, 1 or $10 \mu \mathrm{M}$ BSO significantly enhanced GSH depletion in arsenic trioxide-treated A549 (29) and HeLa cells (30). These data suggest that BSO differently influences the GSH levels depending on the cell type and co-incubation drugs.

Conclusively, PG inhibited the growth of ECs, especially CPAEC via apoptosis. PG-induced EC death was related to GSH depletion rather than ROS level. Since little is known about the relationship between PG and ECs, our preliminary results provide important information on the antigrowth mechanisms of PG in ECs in relation to ROS and GSH.

\section{Acknowledgements}

This study was supported by a grant of the Korea Healthcare Technology R\&D Project, Ministry for Health, Welfare and Family Affairs and Republic of Korea (A084194) and the Korea Research Foundation Grant funded by the Government of the Republic of Korea (MOEHRD).

\section{References}

1. Saeki K, Hayakawa S, Isemura M and Miyase T: Importance of a pyrogallol-type structure in catechin compounds for apoptosisinducing activity. Phytochemistry 53: 391-394, 2000.
2. Yamada J, Yoshimura S, Yamakawa H, Sawada M, Nakagawa M, Hara S, Kaku Y, Iwama T, Naganawa T, Banno Y, et al: Cell permeable ROS scavengers, Tiron and Tempol, rescue PC12 cell death caused by pyrogallol or hypoxia/reoxygenation. Neurosci Res 45: 1-8, 2003.

3. Gonzalez C, Sanz-Alfayate G, Agapito MT, Gomez-Nino A, Rocher A and Obeso A: Significance of ROS in oxygen sensing in cell systems with sensitivity to physiological hypoxia. Respir Physiol Neurobiol 132: 17-41, 2002.

4. Baran CP, Zeigler MM, Tridandapani S and Marsh CB: The role of ROS and RNS in regulating life and death of blood monocytes. Curr Pharm Des 10: 855-866, 2004.

5. Zorov DB, Juhaszova M and Sollott SJ: Mitochondrial ROSinduced ROS release: An update and review. Biochim Biophys Acta 1757: 509-517, 2006.

6. Zelko IN, Mariani TJ and Folz RJ: Superoxide dismutase multigene family: a comparison of the CuZn-SOD (SOD1), MnSOD (SOD2), and EC-SOD (SOD3) gene structures, evolution, and expression. Free Radic Biol Med 33: 337-349, 2002.

7. Wilcox CS: Reactive oxygen species: roles in blood pressure and kidney function. Curr Hypertens Rep 4: 160-166, 2002.

8. Wallach-Dayan SB, Izbicki G, Cohen PY, Gerstl-Golan R, Fine A and Breuer R: Bleomycin initiates apoptosis of lung epithelial cells by ROS but not by Fas/FasL pathway. Am J Physiol Lung Cell Mol Physiol 290: L790-L796, 2006.

9. Simon HU, Haj-Yehia A and Levi-Schaffer F: Role of reactive oxygen species (ROS) in apoptosis induction. Apoptosis 5: 415-418, 2000

10. Moreno-Manzano V, Ishikawa Y, Lucio-Cazana J and Kitamura M: Selective involvement of superoxide anion, but not downstream compounds hydrogen peroxide and peroxynitrite, in tumor necrosis factor-alpha-induced apoptosis of rat mesangial cells. J Biol Chem 275: 12684-12691, 2000.

11. Sawada M, Nakashima S, Kiyono T, Nakagawa M, Yamada J, Yamakawa H, Banno Y, Shinoda J, Nishimura Y, Nozawa Y, et al: p53 regulates ceramide formation by neutral sphingomyelinase through reactive oxygen species in human glioma cells. Oncogene 20: 1368-1378, 2001.

12. Han YH, Kim SZ, Kim SH and Park WH: Pyrogallol inhibits the growth of lung cancer Calu-6 cells via caspase-dependent apoptosis. Chem Biol Interact 177: 107-114, 2009.

13. Han YH, Kim SZ, Kim SH and Park WH: Apoptosis in pyrogallol-treated Calu- 6 cells is correlated with the changes of intracellular GSH levels rather than ROS levels. Lung Cancer 59: 301-314, 2008.

14. Bassenge E: Endothelial function in different organs. Prog Cardiovasc Dis 39: 209-228, 1996.

15. Park WH, Seol JG, Kim ES, Hyun JM, Jung CW, Lee CC, Kim BK and Lee YY: Arsenic trioxide-mediated growth inhibition in MC/CAR myeloma cells via cell cycle arrest in association with induction of cyclin-dependent kinase inhibitor, p21, and apoptosis. Cancer Res 60: 3065-3071, 2000.

16. Han YH, Kim SH, Kim SZ and Park WH: Caspase inhibitor decreases apoptosis in pyrogallol-treated lung cancer Calu-6 cells via the prevention of GSH depletion. Int J Oncol 33: 1099-1105, 2008.

17. Han YH, Kim SZ, Kim SH and Park WH: Arsenic trioxide inhibits growth of As4.1 juxtaglomerular cells via cell cycle arrest and caspase-independent apoptosis. Am J Physiol Renal Physiol 293: F511-F520, 2007.

18. Bailey HH: L-S,R-buthionine sulfoximine: historical development and clinical issues. Chem Biol Interact 111-112: 239-254, 1998.

19. Yang J, Liu X, Bhalla K, Kim CN, Ibrado AM, Cai J, Peng TI, Jones DP and Wang X: Prevention of apoptosis by Bcl-2: release of cytochrome c from mitochondria blocked. Science 275: $1129-1132,1997$.

20. Oberley LW and Oberley TD: Role of antioxidant enzymes in cell immortalization and transformation. Mol Cell Biochem 84: 147-153, 1988.

21. Poulose SM, Harris ED and Patil BS: Citrus limonoids induce apoptosis in human neuroblastoma cells and have radical scavenging activity. J Nutr 135: 870-877, 2005.

22. Han YH, Kim SH, Kim SZ and Park WH: Intracellular GSH levels rather than ROS levels are tightly related to AMA-induced HeLa cell death. Chem Biol Interact 171: 67-78, 2008.

23. Park WH, Han YW, Kim SH and Kim SZ: A superoxide anion generator, pyrogallol induces apoptosis in As4.1 cells through the depletion of intracellular GSH content. Mutat Res 619: 81-92, 2007. 
24. Li JJ, Tang Q, Li Y, Hu BR, Ming ZY, Fu Q, Qian JQ and Xiang JZ: Role of oxidative stress in the apoptosis of hepatocellular carcinoma induced by combination of arsenic trioxide and ascorbic acid. Acta Pharmacol Sin 27: 1078-1084, 2006.

25. Khan NS, Ahmad A and Hadi SM: Anti-oxidant, pro-oxidant properties of tannic acid and its binding to DNA. Chem Biol Interact 125: 177-189, 2000.

26. Estrela JM, Ortega A and Obrador E: Glutathione in cancer biology and therapy. Crit Rev Clin Lab Sci 43: 143-181, 2006.

27. Lewis-Wambi JS, Kim HR, Wambi C, Patel R, Pyle JR, KleinSzanto AJ and Jordan VC: Buthionine sulfoximine sensitizes antihormone-resistant human breast cancer cells to estrogeninduced apoptosis. Breast Cancer Res 10: R104, 2008.
28. Ramos AM and Aller P: Quercetin decreases intracellular GSH content and potentiates the apoptotic action of the antileukemic drug arsenic trioxide in human leukemia cell lines. Biochem Pharmacol 75: 1912-1923, 2008.

29. Han YH, Kim SZ, Kim SH and Park WH: Induction of apoptosis in arsenic trioxide-treated lung cancer A549 cells by buthionine sulfoximine. Mol Cells 26: 158-164, 2008.

30. Han YH, Kim SZ, Kim SH and Park WH: Enhancement of arsenic trioxide-induced apoptosis in HeLa cells by diethyldithiocarbamate or buthionine sulfoximine. Int J Oncol 33: 205-213, 2008 . 